\title{
Status of BSIT Program in Region 4B SUCs: Basis for Regional Qualification Framework towards ASEAN Connectivity
}

\author{
A. Garcia and M. Marigmen
}

\begin{abstract}
This paper aimed to determine the status of Bachelor of Science in Information Technology (BSIT) program among State Universities and Colleges (SUCs) in Mindoro, Marinduque, Romblon and Palawan (MIMAROPA) Region 4B, Philippines in terms of administration qualification, teacher competency, infrastructure, and student competency basis for regional qualification framework towards ASEAN connectivity. Thirty-seven (37) BSIT program heads/directors and teachers and $2444^{\text {th }}$ year BSIT students were participants of the study. Findings revealed that administration qualification among teachers was low which indicates that the teacher qualifications needs to be improved and strengthened. Findings also revealed that teacher competency is on the high extent which shows that teachers are competent to teach the assigned subjects. The infrastructures were proved as on the high extent which indicates that SUCs in MIMAROPA provides good services to the needs of the BSIT students. Lastly, the student competency revealed as high which shows that student acquire the basic knowledge and skills. However, there are some areas or skills that need to be enhanced to be eligible to ASEAN member countries. But as for local and national level, the BSIT program among SUCs in MIMAROPA are complaint with the basic standards. Based on the result, the proposed regional qualification framework to improve the teachers and students competencies is recommended to be eligible and skilled in the ASEAN Economic Community.
\end{abstract}

Index Terms-BSIT program, competency-based, ASEAN connectivity, regional qualification framework.

\section{INTRODUCTION}

Today, Information Technology (IT) is universally regarded as an essential tool in enhancing the competitiveness of the economy of a country [1]. As innovations continue to increase and evolve, more and more Information Technology (IT) professionals are needed. Career opportunities in the technology world are without limits. Everybody can contribute in many areas, while making their own work meaningful and rewarding, wherever they choose to be.

Many institutions around the globe offers Information Technology program to response to the demands of Information Technology (IT) professionals [2]. The Bachelor of Science (B.S.) program in Information Technology (IT) is a Bachelor's degree granted for an undergraduate course or program in the Information technology field. The degree is

Manuscript received November 16, 2019; revised on May 9, 2020.

The authors are with the Occidental Mindoro State College, Occidental Mindoro, Philippines (email: ailenc2004@yahoo.com, mbmarigmen@yahoo.com). normally mandatory in order to work in the Information technology industry. It offers an interdisciplinary curriculum focusing on Information Technology. The program is unique in that it merges traditional academic topics with leading edge and current IT practices and technology [2].

In the Philippines, Bachelor of Science in Information Technology is under the Commission on Higher Education (CHED), the official governing body of higher education institutions. It provides and mandates the minimum requirement of the said program. The CHED Memorandum Order (CMO) 25 series of 2015 [3] states that the Bachelor of Science in Information Technology (BSIT) program includes the study of the utilization of both hardware and software technologies involving planning, installing, customizing, operating, managing and administering and maintaining information technology infrastructure that provides computing solutions to address the needs of an organization.

Teachers across the world are coming under ever-increasing pressure to respond to rapid changes in society, to become more responsive to the needs of their students and more accountable for their learning outcomes [4]. The demands for accountability have led to an increasing emphasis in the educational discourse on teacher competencies, deriving from a belief that specifying more precisely the knowledge and skills effective teachers should have will lead to enhanced teacher quality and, in turn, improved student learning outcomes [5].

In addition, the infrastructure offered by the institution should respond to the needs of the students and teachers. It greatly affects the performance of the students and teachers, especially in the field of information technology. The Information and communication technology (ICT) infrastructure, according to Pradhan [6] plays a substantial role in catalyzing economic growth, especially in today's era of internet and mobile telecommunication.

The changing realities spurred by globalization underscore the shift in contemporary international education discourse from education to lifelong learning, and from education as transmission to expert knowledge to education as building learner competencies-including learning how to learn. These are realities that Philippine higher education institutions (HEIs) are already facing as they compete in a global and regional arena, where borders are starting to disappear.

Furthermore, the Department of Education (DepEd) Secretary Leonor Magtolis Briones [7] recently underscored the importance of the alignment of the Philippine Qualification Framework (PQF) to those of other Association of Southeast Asian Nations (ASEAN) Member States in supporting lifelong learning and the mobility of the Filipino 
learners and workers.

The Philippines as member of the ASEAN Economic Community acknowledge the ASEAN integration in its full implementation on 2015. The ASEAN Qualification Reference Framework (AQRF) [8] is a common reference framework that enables comparisons of education qualifications across participating ASEAN Member States (AMS) [9]. One of its objectives is to "encourage the development of qualifications frameworks that can facilitate lifelong learning".

The higher education institutions (HEIs) in the Philippines are implementing the ASEAN integration. Yet, many institutions are not yet ready with the integration. With this, HEIs are exerting effort to assess and evaluate the teaching and learning process of each program being offered to improve more in order to keep abreast to Asian countries.

In this regard, several studies and reforms had been created and implemented with each of the member countries of ASEAN up to the present times. The aim is to improve the IT status of their respective country including the competency or skills of the graduates as they join in the field of work in the ASEAN community.

With the cited situations, the researcher is encouraged to conduct this study to identify the status of BSIT program offered by SUCs in MIMAROPA. The study aimed to recognize the relationships among the categories of the ASEAN IT standards with the status of the BSIT program and propose a regional qualification framework towards ASEAN integration that will help the schools to be at par with Asian countries and the world as well.

\section{Procedure FOR PAPER SUBMISSION}

\section{A. Research Design}

Based on the nature of the study, descriptive-correlational research design was utilized. According to Salkind [10], descriptive research asks about the characteristics of a phenomenon. It will describe the status of the school which includes teacher competency, administration qualification, infrastructure and the student competency.

On the other hand, correlational technique was employed to assess the degree of relationship among the status of the BSIT program such as the independent variables are teacher competency, administration qualification and infrastructure to the dependent variable which is the student competency. $\mathrm{He}$ also states that correlational research describes a linear relationship between variables. It also imply that variable share something in common.

Descriptive study described the status of BSIT program with the following ASEAN IT standard categories: student competency, teacher competency and infrastructure were answered by randomly selected $4^{\text {th }}$ year students. The Administration qualification questions were answered by the deans, program heads, and faculty.

\section{B. Description of the Sample}

The respondents of the study were the program heads/director, faculty members and selected $4^{\text {th }}$ year students of BSIT program main campus only. A total of 37 BSIT administration and 244 BSIT $4^{\text {th }}$ year students of the
State Universities and Colleges in MIMAROPA that offers Bachelor of Science in Information Technology namely Occidental Mindoro State College, Mindoro State College of Agriculture and Technology, Romblon State University and Palawan State University were chosen as respondents using simple random sampling. The selection of the respondents was based on the sample of the population of BSIT $4^{\text {th }}$ year students among the State Universities and Colleges in MIMAROPA region. However, the entire population or $(100 \%)$ of BSIT program are included which includes the deans, program heads and faculty.

\section{Data Gathering Tool}

The self-made questionnaire was used as the main source of data collection in the study. It is based on the ASEAN Information Technology Standard which are implemented in ASEAN members and the standards are anchored in Association in Computing Machinery (ACM) and the Institute of Electrical and Electronics Engineers (IEEE). The first part measures the student competency which consists of the 4 domains of ASEAN qualification reference framework which contains the Knowledge, Skills, Application and Responsibility, answered by the students. The second part measures the administration qualification which consists Professional development which includes Seminars and Trainings, IT short courses, Industry Immersion Experience, and Research, Development and Professional Organization Membership which were accomplished by the BSIT administration (deans, program head/director and the faculty members). The third part measures the infrastructure which includes learning environment, Laboratory, Library and Industry availability were accomplished by the students.

A letter of request duly noted by the researcher's adviser was sent to the University/College President requesting for permission from the respective University and College President or College Officials. Proper etiquette and procedure in data gathering were observed. It underwent to several signatures for documentation purposes before the University or College President approved the request. The distribution of questionnaires was started during the month of January, 2018. The questionnaires were personally distributed to the randomly selected respondents with proper instructions and responses were treated confidentially.

\section{RESUlT AND DISCUSSION}

Fig. 1 presents the result summary of the mean level of professional development, teacher competency and infrastructure of the SUCs in MIMAROPA using the 5-point Likert scale. Findings revealed that administration qualification or professional development among teachers was low which indicates that the teacher qualifications needs to be improved and strengthened. Findings also revealed that teacher competency is on the high extent which shows that teachers are competent to teach the assigned subjects. The infrastructures were proved as on the high extent which indicates that SUCs in MIMAROPA provides good services to the needs of the BSIT students. Lastly, the student competency revealed as high which shows that student acquire the basic knowledge and skills. However, there are some areas or skills that need to be enhanced to be eligible to 
ASEAN member countries. But as for local and national level, the BSIT program among SUCs in MIMAROPA are complaint with the basic standards.

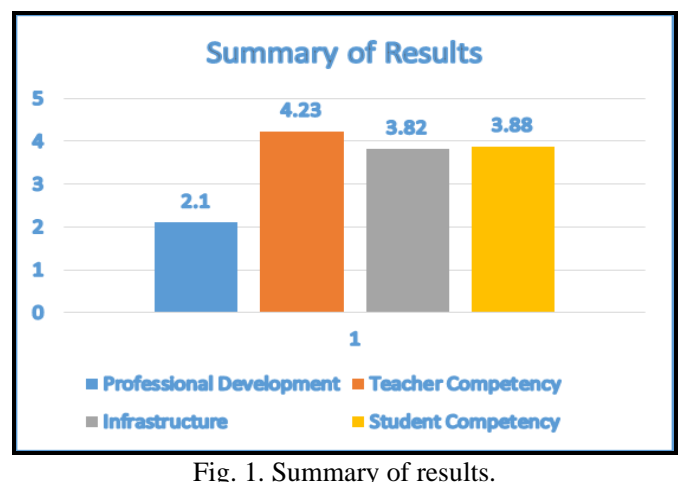

There is a significant relationship between the administration qualification or professional development and the student competency. Result indicates that the six indicators of administration qualification or professional development as dependent variables were analyzed and computed using the stepwise technique. In each regression analysis the four indicators in student competency such as knowledge, application, responsibility and skills were simultaneously entered into the regression model. Among the six indicators, seminars and trainings and development/innovation are the best predictor which have the p-value $<=0.05$. This implies that the teachers seminars and trainings is highly contributes the students acquired competency. Likewise, the participation of teachers in the system or software development/innovation can greatly contribute or influence the skills imparted by the teachers to the students. The result is supported in the study of Avalos [11], which states that professional development is about teachers learning, learning how to learn, and transforming their knowledge into practice to the benefit of their students' growth.

There is a significant relationship between the teacher competency and the student competency. The four indicators of teacher competency as dependent variables were analyzed and computed using the stepwise technique. In each regression analysis the four indicators in student competency such as knowledge, application, responsibility and skills were simultaneously encoded into the regression model. Among the four indicators the best predictors are professional knowledge and skills having the p-value $<=0.05$. This indicates that the knowledge and skills of the teacher are highly predictors and influence in attaining student competency. Result is reinforced with the study of Davies [12], which states that as an educator or a member of education field, continuous learning is important in order to avoid career stagnation.

Likewise, Dulay [13] also recommended that the teachers should pay attention to their professional growth. Teachers should develop innovation and strategies that can further improve their teaching competence.

There is a significant relationship between the infrastructure and the student competency. The four indicators of infrastructure as dependent variables were analyzed and computed using the stepwise technique. In each regression analysis the four indicators in student competency such as knowledge, application, responsibility and skills were simultaneously encoded into the regression model. Laboratory facilities, Library and IT industry are among the indicators that have the highest predictors and influence to the student competency having the $p$-value of $<=0.05$. This implies that the facilities in the laboratory can greatly affect the student competencies, the resources in the library which reinforce student knowledge and the availability of IT industry which can alleviate student skills by deploying them in their On-the-Job Training (OJT). The result is supported by Thuan [14] which states growing body of research has found that school facilities can have a profound impact on both teacher and student outcomes and the overall honing of the students.

This finding implies that there is a significant difference in the level of teacher competency acquired by the teachers as perceived by the students in the different SUCs in MIMAROPA for the professional knowledge, skills, characteristics and ethical standards. They have different ways to achieve the teacher knowledge, skills, characteristics and ethical standards. It reflects on how they implement and perform in their respective classes. It is supported by Brown Center on Education Policy [15] empirical research that teachers differ dramatically from one another in effectiveness.

Result implies that there is a significant difference of the level infrastructure among MIMAROPA SUCs across indicators. This implies that there is a significant difference in the level of infrastructure offered by institution as perceived by the students in the different SUCs in MIMAROPA for the learning environment, laboratory facilities, library and IT industry. Infrastructure are different depending on the available budget intended for the IT facilities to facilitate and enhance student learning. The finding is supported by the view of Corong [16] which states that the government of the Philippines continues to implement reforms that aim to promote economic development and lift the country's standard of living. It is also supported by Martin [17] which states that no school is like any other. Schools differ, for example, with respect to the socio demographic composition of the student body but also with respect to vital educational outcomes such as students' achievement, learning-related motivation and affect, and learning strategies.

There is a significant difference of the level of student competency among MIMAROPA SUCs across indicators. This finding implies that the level of student competency learned by the students in the different SUCs in MIMAROPA is different for the knowledge, application, responsibility and skills. They have different ways to achieve the knowledge, application, responsibility and skills. It reveals on how they execute, implement and fulfil in their respective classes. It is supported by Weossmann [18] that students in some countries do far better on international achievement tests than students in other countries. Is this all due to differences in what students bring with them to school--socioeconomic background, cultural factors, and the like.

\section{THE PROPOSE FRAMEWORK}

As shown in Fig. 2, the goal in all suggested programs is 
the ASEAN IT and IT industry skills standards. In developing professional qualification for teachers, the school administrator should consider the advanced training of IT professional since as findings revealed that it can influence student performance or competency. If budget warrant, sending them in international seminars or trainings across borders among ASEAN Economic Community.

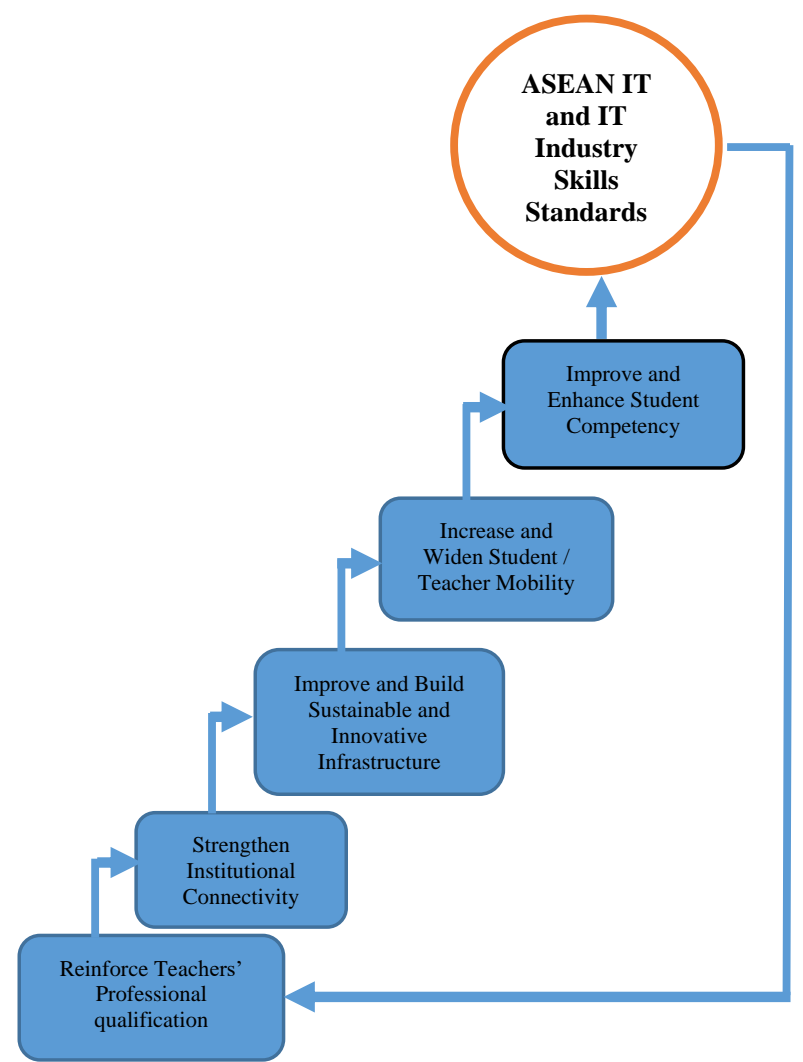

Fig. 2. Proposed regional qualification framework.

In institutional connectivity, it needs to be strengthened and widen the strong partnerships among neighboring institutions, national and ASEAN member countries to share best practices in teaching and collaborate in doing researchers and system development/innovation.

In building sustainable infrastructure, it is best to coordinate existing resources to deliver support across the full life cycle of infrastructure projects in ASEAN, including project preparation, improving infrastructure productivity, and capability building. This strategy also includes exchanging lessons on "smart urbanization" models across ASEAN Member States that can simultaneously deliver economic growth and a good quality of life especially to the students and the whole institution community. On the other hand, improving digital innovation requires the establishment of regulatory frameworks for the delivery of new digital services (including data management and digital financial services); support for the sharing of best practices on open data; and equipping the school community with the capabilities to access these new technologies.

In developing student/teacher mobility includes facilitating travel for tourists by addressing the lack of information on travel options and providing simpler mechanisms to apply for necessary visas across borders of ASEAN community. Additionally, there is an opportunity to strengthen skills mobility in the region and, where appropriate, by establishing high-quality qualification frameworks in critical vocational occupations, and to encourage greater mobility of intra-ASEAN university students. The ASEAN Curriculum Sourcebook (for primary and secondary schools) was developed in 2012, and ASEAN is now working on ways to promote utilization of the Sourcebook, in addition to the existing supplementary materials on ASEAN studies in schools. The website management of the ASEAN Virtual Learning Resource Centre (AVLRC) [19] which focuses on ASEAN's peoples, news, culture, travel, studies and opportunities has been continuing since its soft launch in March 2015.

Lastly, student competency can be achieved through qualified and competent teachers, strong partnerships with other institutions, industries across ASEAN community and sustainable and innovative infrastructure. A cycle of activities will be done although out and is recommended to follow all the suggested programs for the betterment and eligibility of the students.

In the course of formulating the framework, it was subjected to comments and suggestions of experts in Information Technology basing on the findings of the study.

\section{CONCLUSIONS}

The following are the conclusions derived from the findings of the study. There is a need to strengthen the professional development of BSIT teachers among MIMAROPA SUCs. The BSIT teachers possess the standard teacher competency such as professional knowledge, skills, characteristics and ethical standards. The infrastructure among SUCs in MIMAROPA provides better services particularly in learning environment and the availability of IT industry in the respective institutions is the main concern for development. Students possess the required competencies particularly they have the higher sense of responsibility and enhancing the skills are the concern. The administration qualification particularly on professional development strongly influence the student competency. The teacher competency is highly significant and can greatly contribute to the student competency in all indicators. Laboratory facilities and IT industry are highly significant to the student competency among SUCs in MIMAROPA. Professional/Personal ethical standards/values is the most acquired competency among teachers in MIMAROPA SUCs. Learning environment is highly rendered services among the SUCs in MIMAROPA. The application is the most acquired competency among the students of MIMAROPA SUCs compared to knowledge, skills and responsibility.

\section{RECOMMENDATIONS}

The State Universities and Colleges administrators should give opportunities to faculty members to undergo trainings and seminars or advanced training if budget warrants that conforms ASEAN qualification standards. SUCs in MIMAROPA should consider focusing on the availability and accessibility of IT industry and intensify network industries to cater students to enhance students' skills towards ASEAN IT and industry skills standards. Faculty 
should pursue continuous and advanced teacher competency programs particularly in professional knowledge and skills for better learning and teaching for ASEAN student / teacher mobility. MIMAROPA SUCs should develop sustainable and innovative infrastructure that adapts ASEAN standards to reinforce teacher teaching and student learning. The proposed regional qualification framework is recommended to enhance and strengthen the BSIT program among SUCs in MIMAROPA anchored with to ASEAN IT standards. A study focusing on the impact of the proposed regional qualification framework towards ASEAN connectivity is also recommended.

\section{CONFLICT OF INTEREST}

The authors declare no conflict of interest associated with this manuscript.

\section{AUTHOR CONTRIBUTIONS}

The first author made the manuscript from the first to the last phase. The second author made a suggestions by checking the first author's output. Both of them work hand in hand to finish this paper.

\section{ACKNOWLEDGMENT}

To the authors' beloved family for the unconditional love, strength, encouragement and priceless moral and financial support to achieve this endeavor.

Above all, to Almighty God, the source of wisdom, knowledge, strength and good health Who made all these things possible.

\section{REFERENCES}

[1] T. Oliveira and M. F. Martins, "Literature review of information technology adoption models at firm level," Electronic Journal of Information Systems Evaluation, vol. 14, no. 1, p. 110, 2011.

[2] Fairleigh Dickinson University. (2017). Bachelor of science in information technology View.fdu.edu. [Online]. Available: http://view2.fdu.edu/vancouver-campus/academic-programs/bs-infor mation-technology/

[3] CHED. (2015). CHED briefing paper on the status of preparedness of the Philippine higher education for the ASEAN economic community in 2015.

[4] Ed.gov. (2013). Education department releases guidance on providing title IV eligibility for competency-based learned programs. [Online]. Available: http://www.ed.gov/news/pressreleases/ education-department-releases-guidance-providing-title-iv-eligibilitycompetency

[5] L Hayes, R. M. Pringle, and J. Mesa, "Professional development for middle school science teachers: Does an educative curriculum make a difference?" Journal of Science Teacher Education, vol. 28, no. 1, pp. 57-72, 2017.

[6] R. P. Pradhan, G. Mallik, and T. P. Bagchi, "Information communication technology (ICT) infrastructure and economic growth: A causality evinced by cross-country panel data," IIMB Management Review, vol. 30, no. 1, pp. 91-103, 2018.

[7] Leonor Magtolis Briones. (2017). ASEAN qualifications reference framework promotes lifelong learning, mobility of learners and professionals. [Online].

Available: http://www.deped.gov.ph/press-releases

[8] Leonor Magtolis Briones. (2017). ASEAN qualifications reference framework promotes lifelong learning, mobility of learners and professionals. [Online]. Available: http://www.deped.gov.ph/press-releases

[9] S. Charmonman and P. Mongkhonvanit, "Information technology preparation to enter ASEAN community," International Journal of the Computer, the Internet and Management, vol. 22, no. 2, pp. 1-6, 2014.

[10] N. J. Salkind, "100 questions (and answers) about research methods," SAGE, 2011
[11] B. Avalos, "Teacher professional development in teaching and teacher education over ten years," Teaching and Teacher Education, vol. 27, no. 1, pp. 10-20, 2011.

[12] R. S. Davies, "Understanding technology literacy: A framework for evaluating educational technology integration," TechTrends, vol. 55, no. 5 , p. 45,2011

[13] C. Dulay, "The effect of knowledge and skills of teachers in information communication technology (ICT) on the school performance of Towerville high school," 75 Leaves.

[14] K. Q. Thuan and W. T. Liu, "A study of effects of school facilities on learning performance of vocational high school students: An empirical study," Journal of Social Science and Humanities, vol. 1, no. 5, pp. 25-31, 2018.

[15] Brown Center on Education Policy, "Task group on teacher quality," in Evaluating Teachers: The Important Role of Value-Added, vol. 201, S. Glazerman, S. Loeb, D. D. Goldhaber, S. Raudenbush, and G. J. Whitehurst, Eds. Washington, DC: Brown Center on Education Policy at Brookings, 2010.

[16] E. Corong, L. Dacuycuy, R. Reyes, and A. Taningco, "The growth and distributive impacts of public infrastructure investments in the Philippines," in Infrastructure and Economic Growth in Asia, Springer, Cham., 2013, pp. 47-86.

[17] M. Brunner, U. Keller, M. Wenger, A. Fischbach, and O. Lüdtke, "Between-school variation in students' achievement, motivation, affect, and learning strategies: Results from 81 countries for planning group-randomized trials in education," Journal of Research on Educational Effectiveness, 2017.

[18] L. Woessmann, "The importance of school systems: Evidence from international differences in student achievement," Journal of Economic Perspectives, vol. 30, no. 3, pp. 3-32, 2016.

[19] S. B. Das, "Understanding the MPAC," Enhancing ASEAN's Connectivity, 2013, pp. 3-8.

Copyright (C) 2020 by the authors. This is an open access article distributed under the Creative Commons Attribution License which permits unrestricted use, distribution, and reproduction in any medium, provided the original work is properly cited (CC BY 4.0).

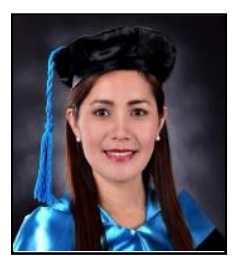

Ailen B. Garcia was born on November 23, 1983 at Libertad, Misamis Oriental, Philippines. She has graduated with a bachelor of science in computer science at Misamis University in 2006. She pursues her master in information technology at Mindanao University of Science and Technology in 2012 and the doctor of education major in educational management at Occidental Mindoro State College in consortium with the Mindoro State College of Agriculture and Technology in 2018 .

She worked as an instructor at Misamis University and later became a program chair of information technology. In 2014, for family reasons she transferred teaching to Occidental Mindoro State College under Information Technology Department as an instructor I until present.

Dr. Garcia is a member of Asia Pacific Consortium of Researchers and Educators (APCoRE) and published a paper in 2019. She also published paper in European Academic Research in 2015 which focuses on text to speech researches. She is also a member of Philippine Schools, Universities and Colleges Computer Education and Systems Society, a non-government organization devoted to the promotion, design, integration and implementation of information and communications technology and other related activities, projects, programs, and endeavors.

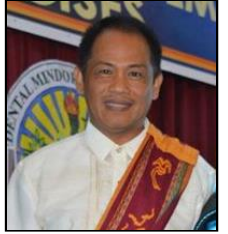

Mario B. Marigmen was born on May 27, 1959 who received a BS degree of agriculture, a master's degree in agronomy minor in environmental science and finished the doctor of philosophy in community development minor in development management.

$\mathrm{He}$ is currently working in Occidental Mindoro State College for almost four decades. He was a graduate school director for eight years and an agriculture faculty at the same time.

Dr. Marigmen is one of the members of the Tamaraw Conservation Organization located in the province of Occidental Mindoro, Philippines which aims to preserve the Tamaraw species. He is also affiliated to many agriculture organizations in the province and the country as well. Many of his papers were published and presented in local, national, and international research fora. 